\title{
Numerical Simulation of Air Flow in Multiple Beds Intensive Care Unit of Hospital
}

\author{
Arvind Kumar Sahu' ${ }^{1}$, Tikendra Nath Verma ${ }^{2, *}$ and Shobha Lata Sinha ${ }^{1}$ \\ ${ }^{1}$ Department of Mechanical Engineering, National Institute of Technology Raipur, \\ Chhattisgarh, India. \\ ${ }^{2}$ Department of Mechanical Engineering, National Institute of Technology Manipur, \\ Langol, Imphal West, Manipur, India. \\ *Email: verma.tikks@ gmail.com \\ Phone: +919827183393
}

\begin{abstract}
Indoor air quality ventilation diminishes airborne respiratory and other transmission in hospitals. Airflow in associate medical care Unit (ICU) may be provided through natural mean and additionally by the assistance of mechanical ventilation. Natural ventilation might not be enough to satisfy the requirement of ventilation for associate degree ICU. In the present study, numerical simulation of the airflow pattern and contaminant movement using Computational Fluid Dynamics (CFD) has been carried out for multiple bed hospital ICU with different inlet angles to examine path of contaminant transfer in the hospital. The measurement of air velocity is used as an input and standard k- $\varepsilon$ turbulence model used in simulation work. Grid Independence Test (GIT) of hospital ICU has been carried out using high-quality tetrahedral unstructured mesh. In order to predict CFD simulations accurately, flow pattern has been validated using model of ICU with four bed and patient occupied with light source. Results shows that increasing rate of air flow change decreases the mean age of air. Importance of outlet position is high for transfer of contaminant particle from ICU.
\end{abstract}

Keywords: CFD; particle dispersion; ventilation.

\section{NOMENCLATURE}
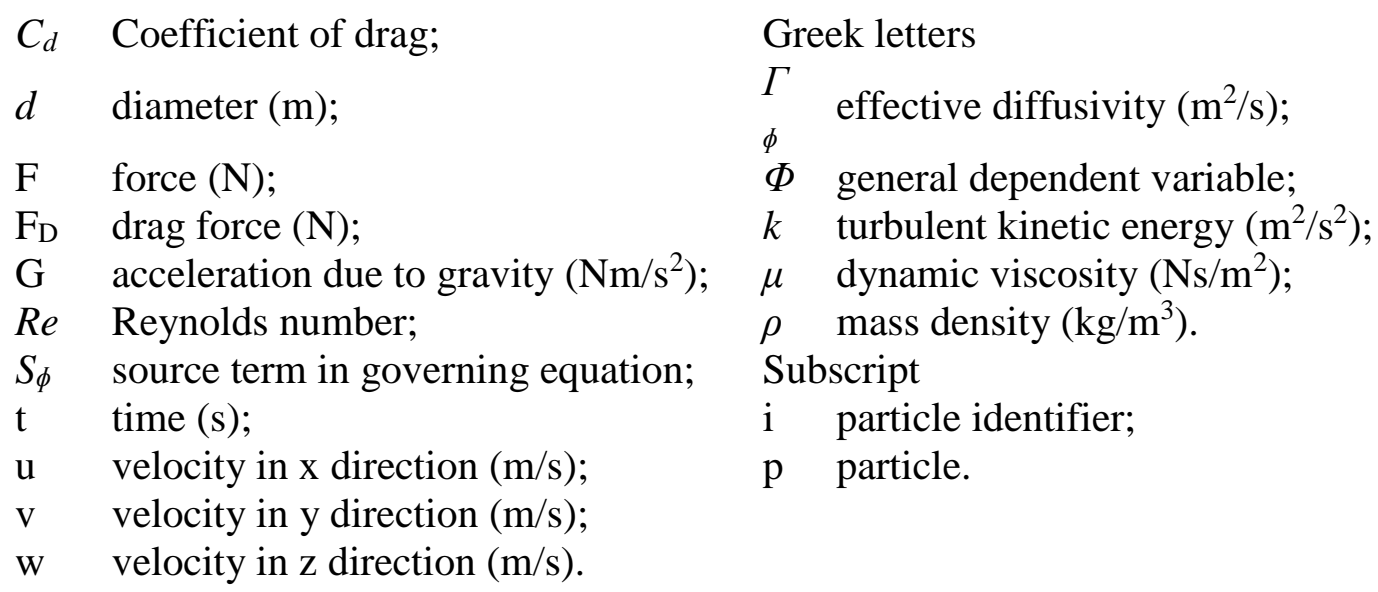


\section{INTRODUCTION}

Protection from indoor and outdoor pollutants is important to deliver health and comfortable atmosphere in the ICU. Indoor and outdoor pollutants are present inside Intensive care unit (ICU) which may possibly in dense form or in the form of fluid. These pollutants are generated outside or inside of the room in which inside generated pollutants is much undesirable and needs to take much care while designing arrangements of air flow inside the ICU [1-2]. Hospital or health service stations square measure the places wherever comparatively high levels of infective (disease-causing) microorganism's generated and so it need rigorous practices and control to safeguard the workers and patient population [3-4].

Air borne particle analysis using numerical and experimental methods in an operating theatre was performed. The effectiveness of differential airflow diffusion system in the reduction of concentration of particle above the operating table was performed. To validate the numerical results, an experiment was carried out to check the entry of internal and external contaminants in the protective area. From the analysis, the experimental results were matched with the numerical solution. The differential air flow diffusion system was able to preserve the desired effect of protection [5]. The effect of locations of exhaust diffusers in an office room using displacement ventilation system was carried out. Simulation was carried out through the release of contaminants from window and door frames using CFD to check the energy consumption and indoor thermal environment for different locations of the exhaust. It was observed that the parameters such as thermal indoor environment, indoor air quality, thermal comfort and energy savings (up to 25\%) were improved through combination of exhaust outlets and room heat sources, such as external walls and lamps. The load on cooling coil was also reduced by $13.8 \%[6]$.

The effectiveness of horizontal and vertical laminar airflow ventilation system in reducing distribution and sedimentation of particles carrying bacteria of a surgical clothing system was studied. CFD was used as the numerical tool for the analysis. It was observed that under identical circumstances, the horizontal laminar ventilation systems yield better results. The presence of objects like lamps, surgical team, etc. poses a serious effect on the motion of infectious particles inside the room [7]. The indoor air quality in an intensive care unit (ICU) of a hospital was investigated using commercial CFD platform FLUENT. A turbulent airflow study was conducted to prevent airborne infections and protection of health workers and other patients in the ICU. It was observed that the stagnant zone was not safe and healthy for both health workers and other patients in the ICU and thus proper ventilation arrangement should be provided [8]. Airflow of 2$\mathrm{D}$ room with and without the effect of buoyancy had been studied using numerical simulation method. In the study, SIMPLE and SIMPLEC algorithms were used to analyze the velocity and temperature distribution in a heated room through introduction of warm air stream at various levels for different values of Grashof number $(G r)$ and Reynolds number. It can be noted that increase in $G r$, increases the recirculation thereby, uniform temperature distribution is obtained. The higher location of outlet orifice yield better temperature distribution [9].

It is vital to attain smart ventilation style for the removal of pathogens mobile particles. Computational fluid dynamics (CFD) plays vital role to simulate and analyze ventilation of an intensive care unit [10]. Over all air movement amount, direction and effect of temperature are important parameters for the investigation of ventilation system [11-12]. In this study numerical and experimental simulation of multiple bed ICU is 
carried out. Fluent 15 and Gambit CFD software's are used for simulation and meshing of model room. Air flow at entry of room is assumed turbulent and Standard k-epsilon turbulence model is used for airflow simulation. For optimization of iterations second order upwind scheme is used. The convergence criteria for the air properties (pressure, energy, $\mathrm{k}$ and $\varepsilon$ ) have been assumed to meet when the iteration residuals reach to $10^{-6}$.

\section{METHOD AND MATERIALS}

\section{Governing Equations}

The basic Fluid motion equations i.e. conversation of mass, momentum and energy describes flow of air inside ICU room. The flow equations are described below [13-15]: For two-dimensional turbulent flow:

$$
\frac{\partial(\rho \phi)}{\partial \mathrm{t}}=\frac{\partial}{\partial \mathrm{x}_{\mathrm{i}}}\left(\Gamma_{\phi} \frac{\partial \phi}{\partial \mathrm{x}_{\mathrm{i}}}-\rho \mathrm{u}_{\mathrm{i}} \phi\right)+\mathrm{S}_{\phi}
$$

For three-dimensional turbulent flow:

$$
\frac{\partial(\rho \phi)}{\partial t}=\frac{\partial}{\partial x}\left(\Gamma \phi \frac{\partial \phi}{\partial t}-\rho u \phi\right)+\frac{\partial}{\partial y}\left(\Gamma \phi \frac{\partial \phi}{\partial y}-\rho v \phi\right)+\frac{\partial}{\partial z}\left(\Gamma \phi \frac{\partial \phi}{\partial z}-\rho w \phi\right)+S_{\phi}
$$

Motion of particle can be evaluated by newton's second law of motion using following Eq. (3) and (4).

$$
\begin{aligned}
& \frac{d u_{p}}{d t}=F_{i}, \quad F_{D}=\frac{18 \mu C_{d} \operatorname{Re}}{\rho_{p} d_{p}{ }^{2} \times 24} \\
& \frac{d u_{p}}{d t}=F_{D}\left(u_{i}-u_{p}\right)+\frac{g\left(\rho_{p}-\rho\right)}{\rho_{p}}+F_{X}
\end{aligned}
$$

Here for air properties such as pressure, energy, $\mathrm{k}$ and $\varepsilon$ were assumed to be met when the iteration residual reduced to $10^{-6}$. In current work particle clouds which are coming out from mouth of each patient is tracked out using particle tracking module of fluent 15 software which is based on equation 3 and equation 4. Diameter of particles are considered $10^{-6} \mathrm{~mm}$.

In literatures lots of studies carried out to find possible devolution paths of viruses in ICU room, but an organized study which is based on actual problem of effective ventilation of ICU room with multiple bed has not received ample attention. Objective of present study is to estimate influence of inlet air-flow inclination on ventilation system. Figure 1 shows the arrangement of five bed intensive care unit. Simulation work is carried out for the ICU of BALCO hospital, which is situated in the Korba city of Chhattisgarh. The basic dimensions of ICU are taken same as actual dimensions of hospital, also layout of ICU room is considered same as the hospital. For all the cases, the position of inlet vent, outlet vent and all five patients are kept constant. 


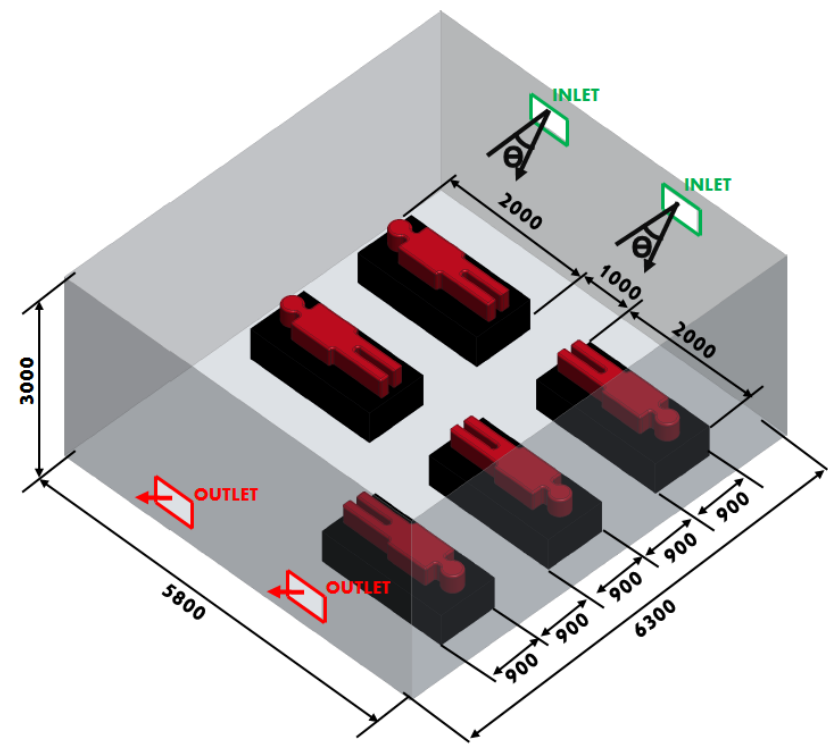

Figure 1. Arrangement of multibed ICU with inlet air inclination, $\Theta$.

As shown in figure 1, ICU room has two inlet vents at north wall and two outlet vents at opposite wall i.e. south wall. Velocity and temperature of fresh air is considered as per literatures and hospital surveys. The temperature of fresh inlet air is considered $20^{\circ} \mathrm{C}$ and for same temperature the properties of fresh air stream is considered. Velocity of fresh air stream is considered $0.4 \mathrm{~m} / \mathrm{s}$. Rectangular cross section considered both for inlets and outlets like a real ICU room. Height and width of inlets as well outlets are 40 $\mathrm{cm}$ and $60 \mathrm{~cm}$ respectively. Location of inlets are $230 \mathrm{~cm}$ above the floor of ICU room. Inlet 1 is situated at $150 \mathrm{~cm}$ and inlet 2 is situated at $370 \mathrm{~cm}$ away from the east wall. Likewise, location of outlets are $30 \mathrm{~cm}$ above the floor and outlet 1 is situated $150 \mathrm{~cm}$ and outlet 2 is situated $370 \mathrm{~cm}$ away from the east wall. Hospital beds are considered rectangular in cross section and its height, width and length are $50 \mathrm{~cm}, 90 \mathrm{~cm}$ and $200 \mathrm{~cm}$ respectively. All the patients are considered like a manikin and its envelopes height, width and length are $30 \mathrm{~cm}, 50 \mathrm{~cm}$ and $180 \mathrm{~cm}$ respectively. The following assumptions have been made for computation:

i. Contaminated particles are assumed to be spherical in shape;

ii. Transfer of mass and heat between contaminant and air are neglected;

iii. No particle reflected on solid surfaces;

iv. Contaminants are assumed to be constant diameter.

\section{Estimation of Grid Independence Test}

Grid independence test (GID) is carried out to refine the grid size and to check performance of the turbulence model. GID is carried out for various interval sizes 100 to 140 for uniform and non-uniform grid structure. Computation domain consists of rectangular room of size $6.3 \mathrm{~m} \times 5.8 \mathrm{~m} \times 3 \mathrm{~m}$. Inlet air flow velocity is $0.2 \mathrm{~m} / \mathrm{s}$ with horizontal air flow direction. For meshing of computational domain, tetrahedral unstructured grid has been used. After grid-independence test of the model, the computational domain has $3.85 \times 10^{5}$ cells. Table 1 shows boundary condition for grid independence test. 
Table 1. Boundary condition for grid independence test (GIT).

\begin{tabular}{lll}
\hline S. No. & \multicolumn{3}{l}{ Boundary Condition } \\
\hline 1 & Inlet & $\mathrm{u}=1, \mathrm{v}=0, \mathrm{w}=0$ \\
& & Temp. $=20^{\circ} \mathrm{C}$ \\
2 & Outlet & $\frac{\partial \boldsymbol{\phi}}{\partial \mathbf{n}}=\mathbf{O}$ \\
3 & Wall & No slip condition \\
\hline
\end{tabular}

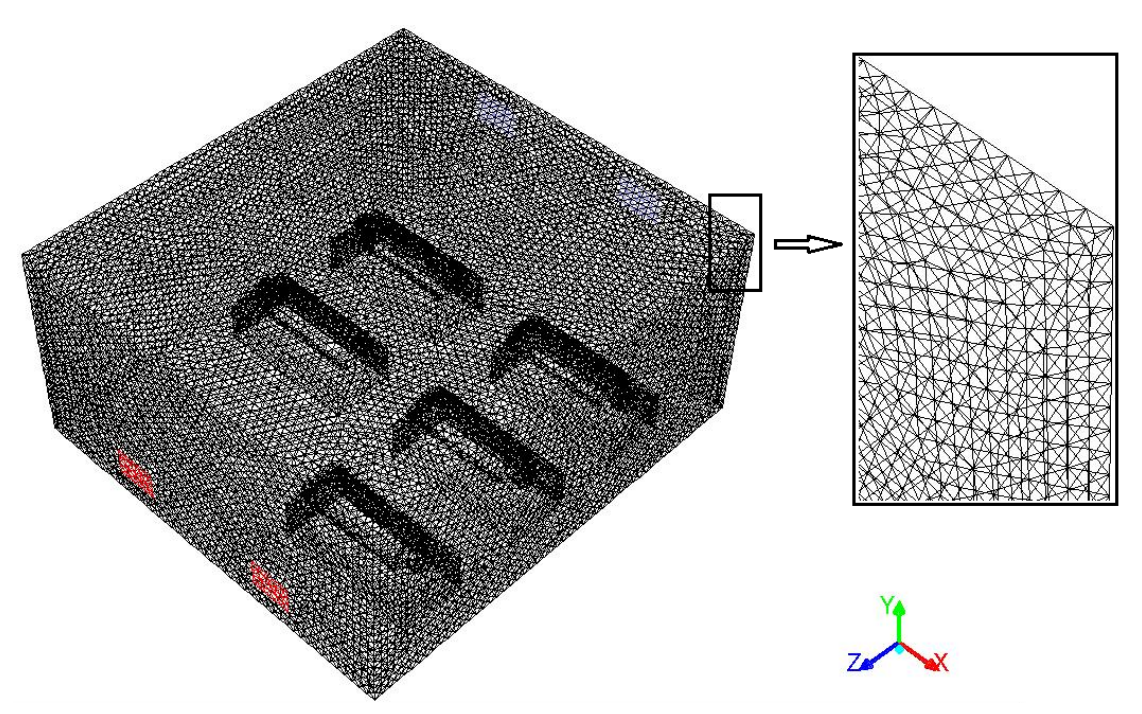

Figure 2. Grid structure.

Figure 3 shows graph between line which passes through the points of $(2.7 \mathrm{~m}, 1.5$ $\mathrm{m}, 0 \mathrm{~m})$ and $(2.7 \mathrm{~m}, 1.5 \mathrm{~m}, 6 \mathrm{~m})$ of the room and air velocity at respective points. Line which passes through centre of computational domain (ICU) has been considered for checking the grid independent solution as near to this line, flow behaviour changes drastically. It is clearly observed from Figure 3 that there is no drastic change in velocity of air stream after grid interval size 120 , which is having $3.8 \times 10^{5}$ cells. So, this grid is chosen for simulation of air flow inside of ICU.

\section{Experimental Validation}

In literatures, most of simulation outcomes are lacking measurement results. Consequently, the reliability of these outcomes isn't well known. A realistic flow problem accounts simulation and experimental results of manifold temperature sources and obstacles in an ICU room. This sets much higher weights on the simulation methods. There are simply several cases of such kind of flow problems. Variation in inside airflow patterns, the quantity of complete inside airflow measurements for comparison and validation of CFD-simulations is extremely restricted. Here scale of experimental model is around 1:3 and light source was also used in experimentation.

Figure 4 shows experimental set up of model room considered for validation. Model room has width, depth and height of the room as $183.5 \mathrm{~cm}, 122.5 \mathrm{~cm}$ and 122.5 $\mathrm{cm}$ respectively. It consists of four patients and beds of sizes $5 \mathrm{~cm} \times 15 \mathrm{~cm} \times 45.5 \mathrm{~cm}$ and $25 \mathrm{~cm}$ x $35 \mathrm{~cm}$ x $50 \mathrm{~cm}$ respectively. Inlet and outlet consist of rectangular cross section 
of size $12 \mathrm{~cm}$ x $20 \mathrm{~cm}$. In order to ensure the required unidirectional airflow at the inlet of the model room, a duct is fabricated. In the model room, fresh air enters through one inlet vent through duct and moves out through outlet vent. The position of inlet vent and outlet vent is opposite to each other. A thermal anemometer is used for velocity measurement during experimentation.

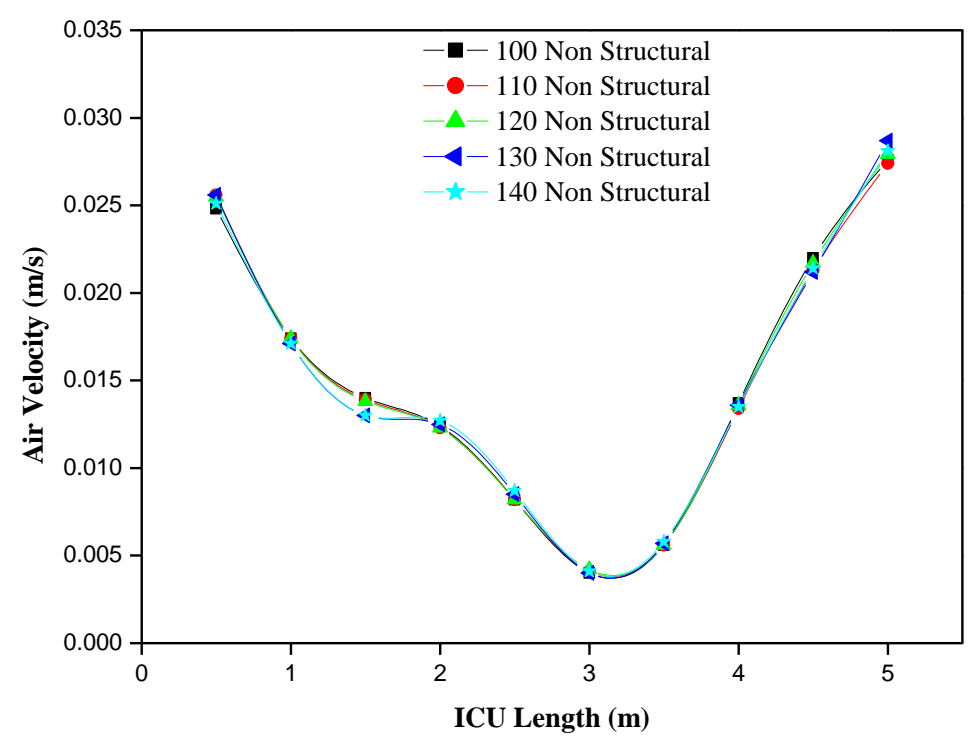

Figure 3. Variation of air velocity and ICU length.

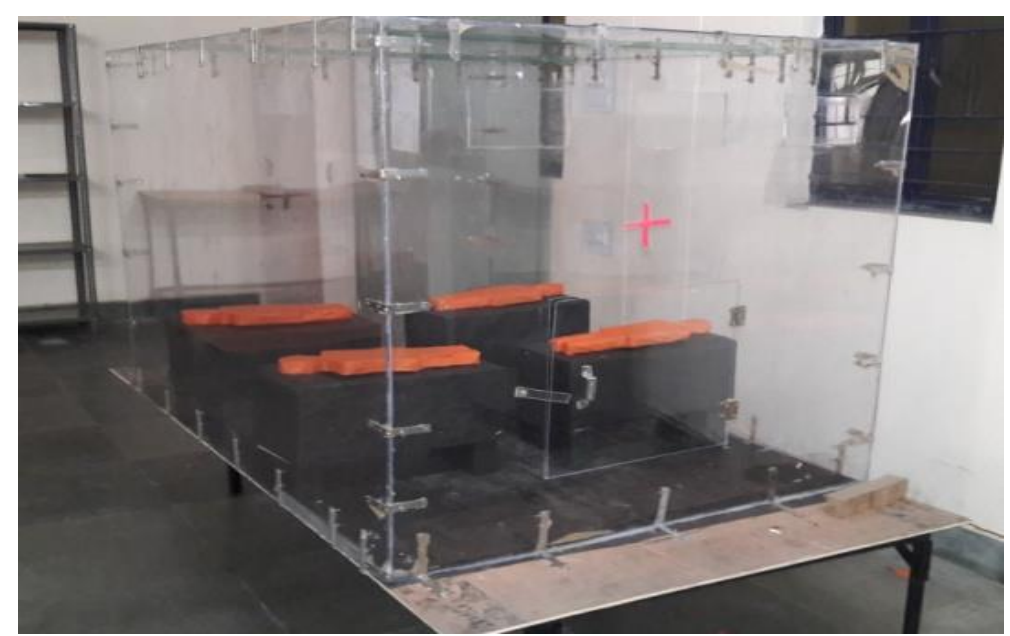

Figure 4. Experimental set up of ICU

\section{RESULTS AND DISCUSSION}

The air flow pattern from the simulation results are compared with the experimental results. Figure 5(b) shows air flow simulation in experimental model. Temperature and velocity of inlet air are considered $20^{\circ} \mathrm{C}$ and $0.2 \mathrm{~m} / \mathrm{s}$ respectively. As seen from Figure 5(a) and 5(b), fresh air from atmosphere enters through inlet and moves horizontally parallel to the roof before striking to opposite wall near to outlet. Fresh air induces throughout experimental room and after striking to opposite wall, it moves towards outlet 
vent. One smaller air re-circulation is found at right bottom corner of model room (between patient and wall near to inlet wall).

Figures 5(a) and 5(b) display comparison between simulated and experimental air flow pattern. It is clearly seen that visualization results follows the simulation results. In both of cases air throws, horizontally from inlet, spread properly inside model room and drops near to outlet vent. Pattern of speeded fresh air is same for both cases, also like simulation results a re-circulation air zone found near to the bottom right corner of model room.

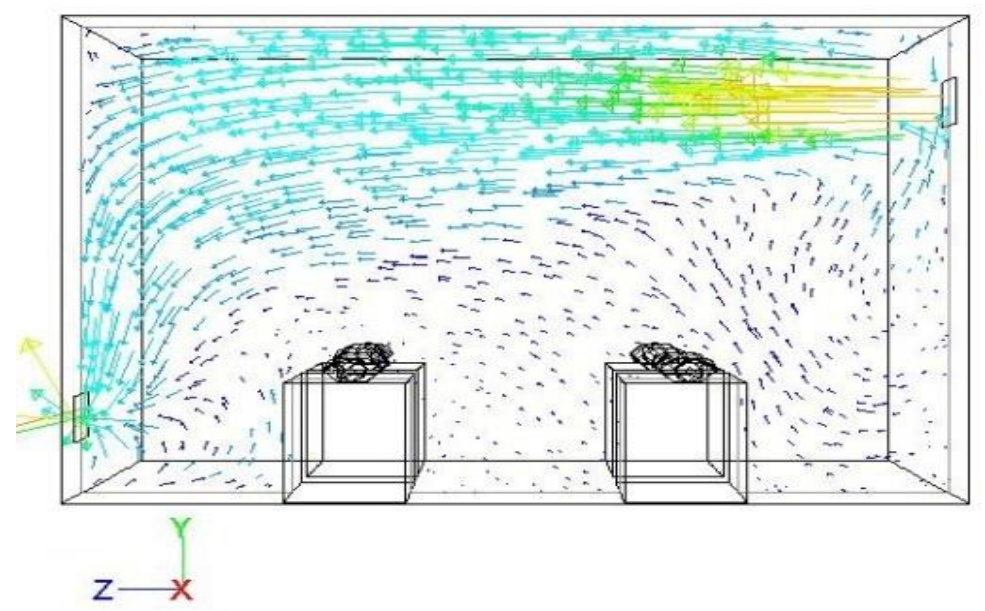

(a) velocity vector at mid plane of ICU.

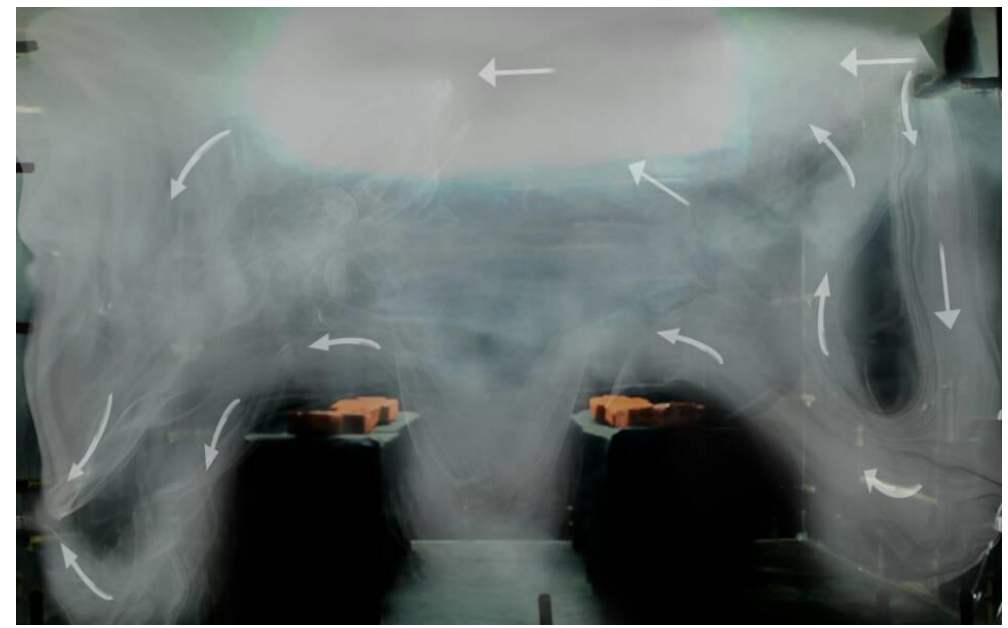

(b) airflow pattern by visualization.

Figure 5. Comparision between simulated and visualization results.

It is observed that ventilation performance depends upon air flow arrangement in hospital. In real ICU, obstacles like medical instruments are present which effects air flow pattern. Here, to be more realistic, patients are considered combination of cylinder and rectangle like a manikin. Fresh air profile is useful to estimate supply air proportion and distribution inside ICU room and to eliminate contaminant entirely from hospital ICU rooms. The air-flow rates should be considered at conventional range of human comfort and noise level. 


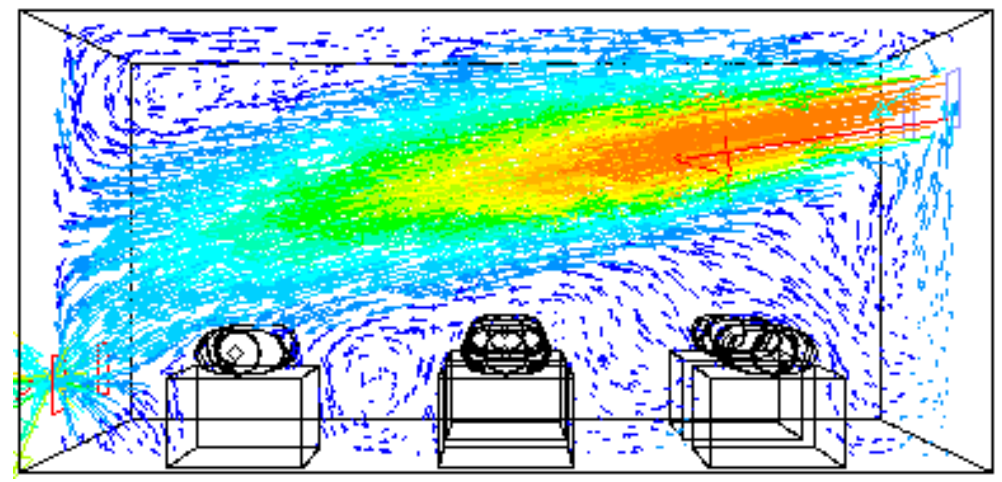

Figure 6. Air flow pattern for five bed ICU room

Figure 6 shows velocity vector for the inlet air inclination $40^{\circ}$ at two center plane of ICU room. As seen from the figure, fresh and cold air is coming from the inlet at inclination with the roof. Velocity and temperature potential core is found at the inlet of ICU room. As compared to the horizontal motion of the air, it is now hitting to south wall near to outlet. It is clearly visible that inlet air drop in this case is higher as compared to horizontal air flow as seen in experimental case. It is seen from figure 6 , a circulation zone is found between patient 2 and patient 3 . If the portion of air gets into contact with the circulation zone, it will move around it and take more time to leave the ICU room which is harmful for patients as well as medical staff.

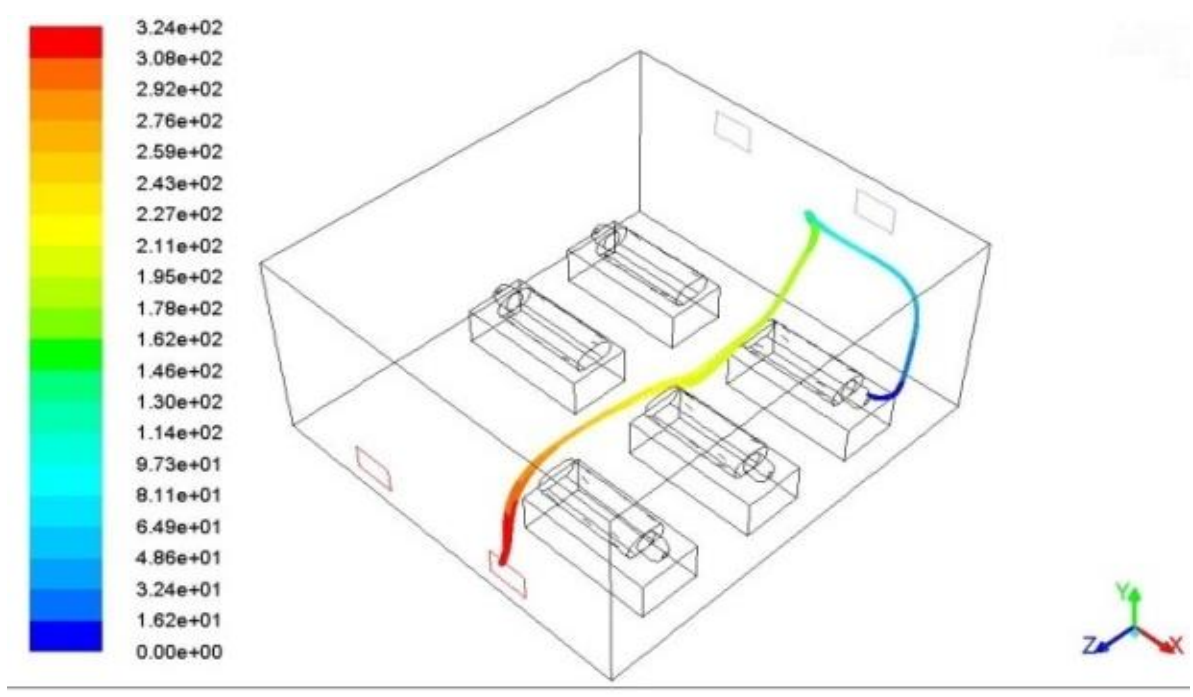

Particle Traces Colored by Particle Residence Time (s)

(a) Patient 1. 


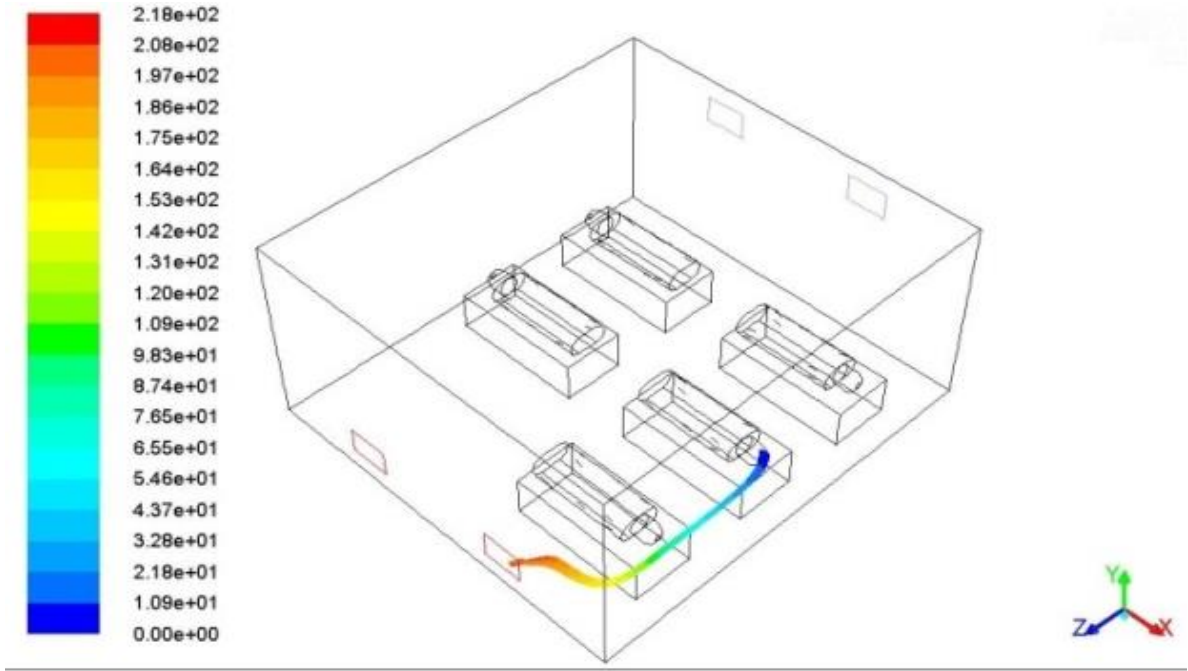

Particle Traces Colored by Particle Residence Time (s)

(b) Patient 2

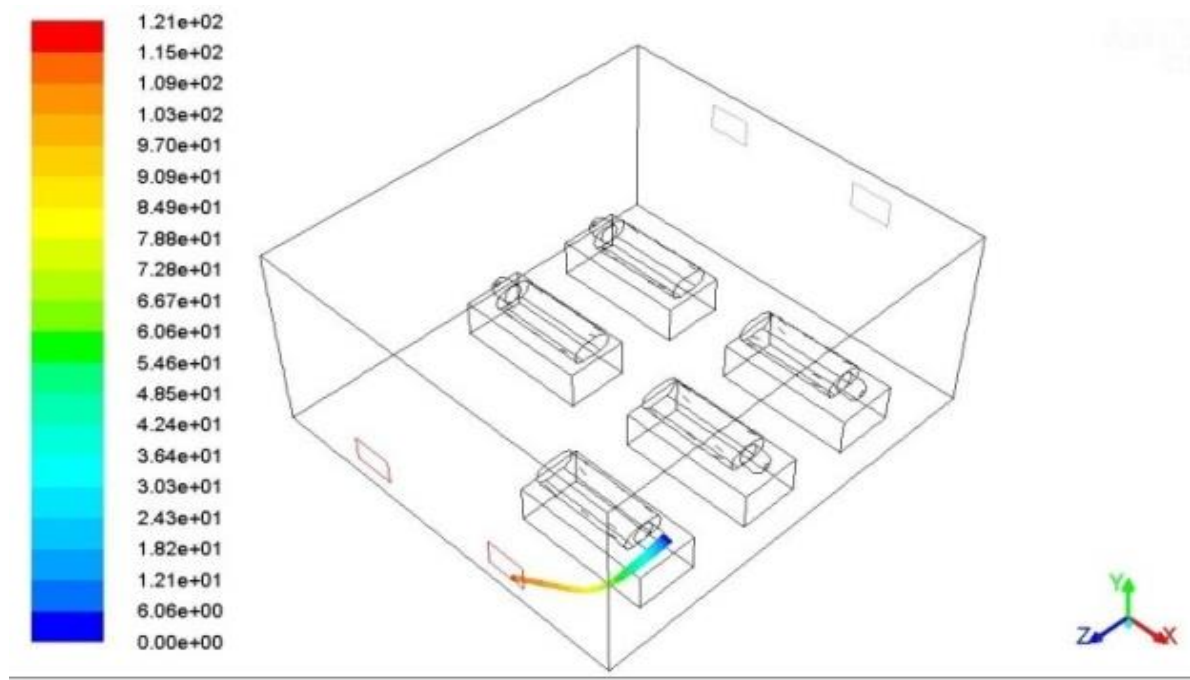

Particle Traces Colored by Particle Residence Time (s)

(c) Patient 3 


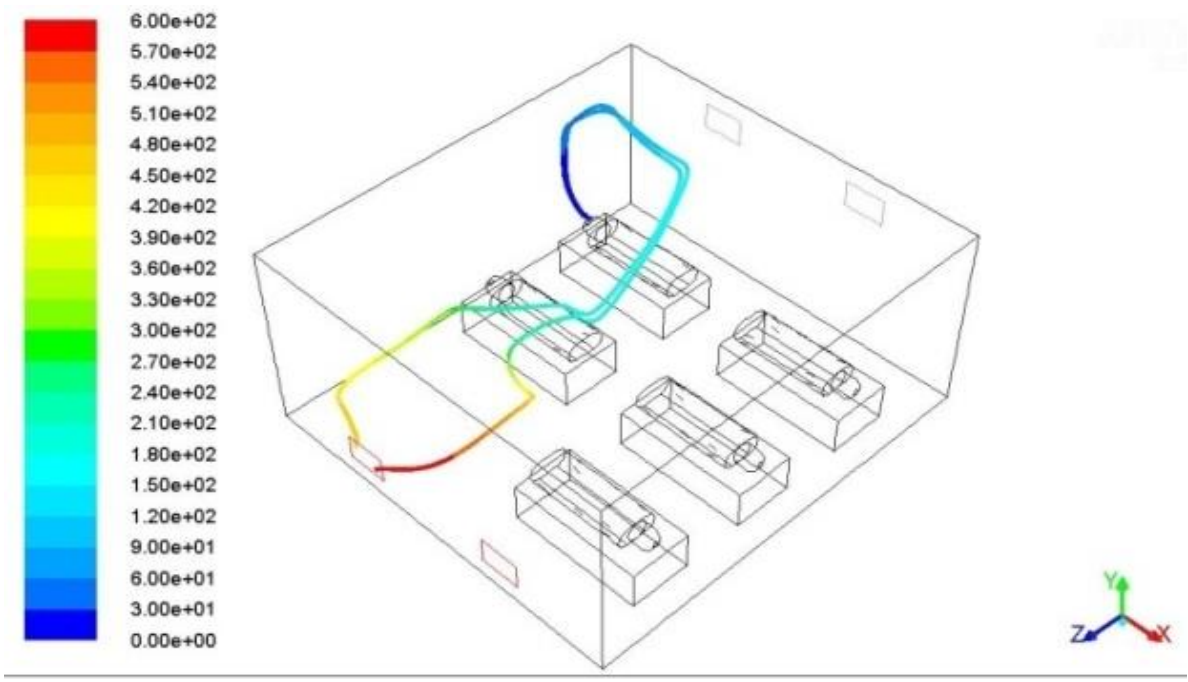

Particle Traces Colored by Particle Residence Time (s)

(d) Patient 4

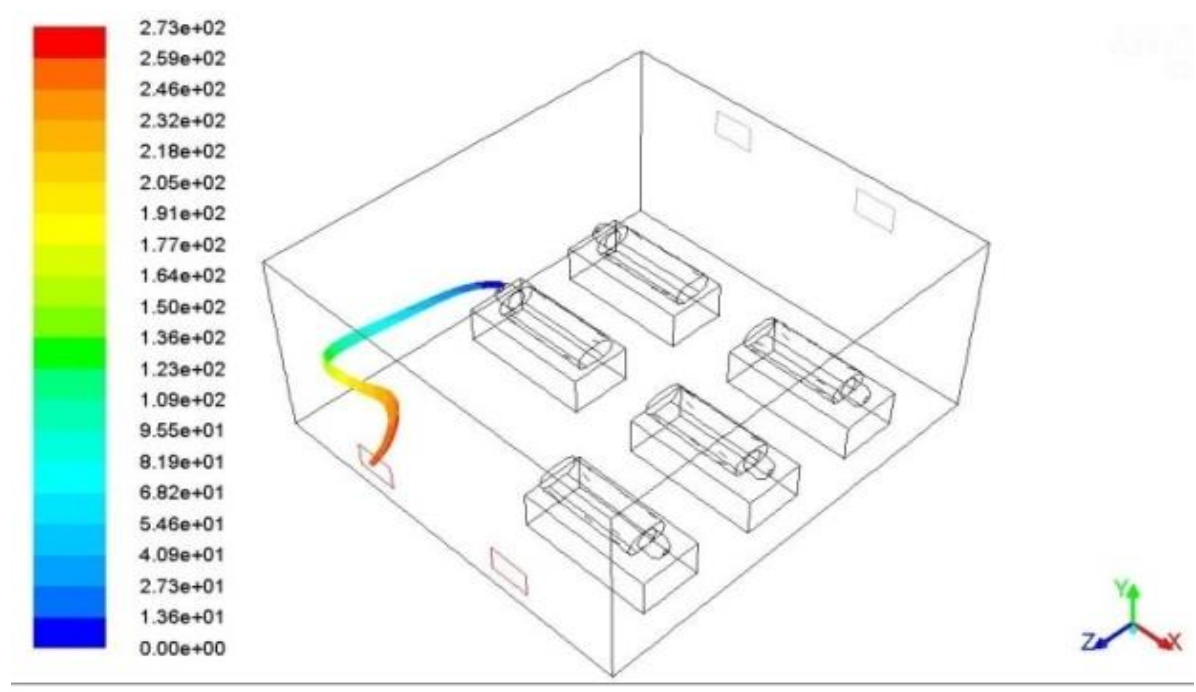

Particle Traces Colored by Particle Residence Time (s)

(e) Patient 5

Figure 7. Movement of contaminant cloud through patients at inlet air angle of $40^{\circ}$.

The studies have been carried out for inlet air velocity $0.4 \mathrm{~m} / \mathrm{sec}$ having different air flow direction $0^{\circ}$ to $80^{\circ}$ with separation of $10^{\circ}$. Total 9 cases of different inlet air flow angle with constant position of inlet, outlet, patient and bed have been considered. Air change per hour is 4 and Reynolds no is 24578 , both are constant. Pattern of result matches with the findings of other investigators [16-17].

Figure 7 (a) to 7(e) show the motion of contaminant particle through patients and time required for a contaminant particle to leave the ICU room for inlet air inclination $40^{\circ}$. As seen from the figures, contaminant particle is coming away from the mouth of each patients, comes into contact with the air, mixes with air and subsequently adding up into touch with the main airstream, follows the path of airstream and leaves the ICU room through the outlet. 
Table 2. Contaminant cloud elimination time from ICU room.

\begin{tabular}{ccccccc}
\hline \multirow{2}{*}{ S. No. } & Inlet air flow & \multicolumn{5}{c}{ Time to leave the ICU (minute) } \\
& angle $\left({ }^{\circ}\right)$ & Patient 1 & Patient 2 & Patient 3 & Patient 4 & Patient 5 \\
\hline 1 & 0 & 4 & 5 & 14 & 5 & 3 \\
2 & 10 & 7 & 4 & 10 & 3 & 4 \\
3 & 20 & 42 & 8 & 25 & 25 & 4 \\
4 & 30 & 8 & 8 & 1 & 1 & 6 \\
5 & 40 & 5 & 3 & 1 & 4 & 2 \\
6 & 50 & 5 & 3 & 2 & 4 & 4 \\
7 & 60 & 6 & 17 & 3 & 23 & 20 \\
8 & 70 & 12 & 54 & 4 & 43 & 19 \\
9 & 80 & 60 & 24 & 21 & 47 & 24 \\
\hline
\end{tabular}

Table 2 compares contaminant cloud elimination time from multiple bed ICU room for different inlet air inclination from $0^{\circ}$ to $80^{\circ}$ (separation of $10^{\circ}$ ). For inlet air inclination of $0^{\circ}$ to $20^{\circ}$, contaminated cloud elimination time is higher side. Average time to eliminate contaminant is 6.2 minutes. For this range it is maximum i.e. 42 minutes for patient 1 at the angle of $20^{\circ}$. Time required for contaminant particle which is coming out from the mouth of all patients, to leave ICU room is less than average value $(15.15$ minutes) for inlet air flow angle of $30^{\circ}, 40^{\circ}$ and $50^{\circ}$. Particles which is coming out from patient 3 takes minimum 1 minutes to leave ICU. The orientation of inlet air flow for $30^{\circ}$ to $50^{\circ}$ inlet air flow angle is good for proper ventilation of ICU for this five bed ICU arrangement, matches with determinations of other investigators [16-17]. Time required for contaminant particle coming out from patients for inlet air angle of $70^{\circ}-80^{\circ}$ is very high than average time value (15.15 minutes) which is dangerous as far as health of patient, nurse/doctor and other people are concerned.

\section{CONCLUSION}

The numerical simulations have been carried out for ICU. Total 8 cases for inlet air flow angles $10^{\circ}$ to $80^{\circ}$ (with interval of $10^{\circ}$ ) have been simulated. Inlet air flow temperature is $20^{\circ} \mathrm{C}$ and inlet air velocity is maintained $0.4 \mathrm{~m} / \mathrm{s}$ for all 8 cases. In this case velocity and temperature potential core drop increases and velocity and temperature potential core throw decreases with increase of inlet air inclination. The orientation of inlet air flow for $30^{\circ}$ to $50^{\circ}$ inlet air flow angle is good for proper ventilation of ICU. For this five bed ICU arrangement, spread of fresh air is found higher for this inlet air inclination. Contaminant cloud elimination time for inlet air inclination $70^{\circ}-80^{\circ}$ is very high than average time value (15.15 minutes) also fresh air spread inside ICU room is lower. Air recirculation zone is found at top of ICU room in front of south wall which is shifted towards occupied zone for higher inlet air inclination also recirculation zone found between patients.

\section{REFERENCES}

[1] Verma TN, Sinha SL. Contaminant Control in Intensive Care Unit of Hospital. Applied Mechanics and Materials. 2014;592-594:2486-2490.

[2] Verma TN, Sinha SL. Contaminant control in intensive care unit (ICU) using CFD modeling. International Journal of Mechanical and Industrial Engineering. 2013;3:121-125. 
[3] Sahu AK, Sinha SL, Verma TN. Numerical Simulation of Air Flow to Ventilate Intensive Care Unit of Hospital. In: Sinha SL, Bikrol H, Dewangan SK, editors. Computer Application in Education \& Research for Science and Technology: International Research Publication House, Delhi. 2018;131-138.

[4] Verma TN, Sahu AK, Sinha SL. Numerical simulation of air pollution control in hospital. Springer Link: Energy Environment and Sustainability. 2018;185-206.

[5] Romano, F, Marocco L, Gusten, J, Joppolo, CM. Numerical and experimental analysis of airborne particles control in an operating theater. Building and Environment. 2015;89-69-379.

[6] Ahmed, QA, Gao, S, Kareem, AK. A numerical study on the effects of exhausts locations on energy consumption and thermal environment in an office room served by displacement ventilation. Energy Conversion and Management. 2016;117:74-85.

[7] Sadrizadeh S, Holmberg S. Surgical clothing systems in laminar airflow operating room: a numerical assessment. Journal of Infection and Public Health. 2014;7:508-516.

[8] Verma TN, Sahu AK, Sinha SL. Study of Particle Dispersion on One Bed Hospital using Computational Fluid Dynamics. Materials Today: Proceeding. 2017;4:10074-10079.

[9] Sinha SL, Arora RC, Roy S. Numerical simulation of two-dimensional room air flow with and without buoyancy. Energy \& Buildings. 2000;32:121-129.

[10] Yam R, Yuen PL, Yung R, Choy T. Re-thinking hospital general ward ventilation design using Computational Fluid Dynamics. Journal of Hospital Infection. 2011;77: 31-36.

[11] Bhamjee M., Nurick A, Madyira DM. An experimentally validated mathematical and CFD model of a supply air window: forced and natural flow. Energy and Building. 2013;57:289-301.

[12] Nielsen PV, Li Y, Buus M, Winther FV. Risk of Cross-Infection in a Hospital Ward with Downward Ventilation. Building and Environment. 2014;45:20082014.

[13] Patankar SV. Numerical Heat Transfer and Fluid Flow. McGraw Hill: Washington. 1980.

[14] Versteeg, Malalasekera. An introduction to computational fluid dynamics. Longman. 1995.

[15] Ghoshdastidar PS. Computer simulation of Flow and Heat Transfer. Tata McGraw-Hill Publishing Company Limited. 1998.

[16] Verma TN, Sinha SL. Trajectory of Contaminated Particle In Intensive Care Unit Of Hospitals Using Numerical Modeling. International Journal on Design \& Manufacturing Technologies. 2015;9:1-5.

[17] Verma TN, Sinha SL. Numerical simulation of contaminant control in multipatient intensive care unit of hospital using Computational Fluid Dynamics. Journal of Medical Imaging and Health Informatics. 2015;9:1-5. 